\title{
Frede and Patzig on Definition in Metaphysics Z.10 and 11
}

\author{
ROBERT HEINAMAN
}

One of the many difficulties presented by Book Z of Aristotle's Metaphysics concerns the account of definition in chapters 10 and 11, an account which has been interpreted in a variety of ways. I believe that confusion on this issue has resulted from commentators' failure to acknowledge Aristotle's distinction between definitions of composites of form and matter, which must specify material parts, and definitions of forms alone, which must not mention material parts - a distinction mirrored in $D e$ Anima I.1's discussion of the definition of composite psychological events and their forms. Hence, when Meta. Z.11 explains that "some" items (1036b23) cannot be defined without reference to material parts, instead of taking this as a remark on the definition of composite substances, commentators often conclude that Aristotle holds that certain forms must be defined with reference to material parts.

In their splendid commentary on Book Z of Aristotle's Metaphysics, ${ }^{1}$ Michael Frede and Günther Patzig have argued that the discussion of definition in chapters 10 and 11 deals with one kind of definition only, viz. the definition of forms. While they do not think that the definition of a form makes an explicit reference to matter, they nevertheless assert that Aristotle's statement in Z.11 that "the animal is perceptible and cannot be defined without change, nor therefore without its parts in a certain condition" (1036b28-30) is a claim about defining forms. ${ }^{2}$ According to them, Aristotle's point is not that such forms are defined with an explicit reference to matter, but rather that such definitions of forms "must make clear the inner connection between form and matter." 3 So if an animal's form is defined by defining its soul, ${ }^{4}$ the definition will make clear that inner

Accepted February 1997

${ }^{1}$ Aristoteles “Metaphysik”: Text, Übersetzung und Kommentar (Munich, 1988), vol. II.

2 Frede and Patzig, pp. 209-13.

3 Frede and Patzig, p. 212. Cf. M. Frede, "The Definition of Sensible Substance in Metaphysics Z," in P. Pellegrin (ed.), Biologie, logique et métaphysique (Paris, 1990), pp. 117-21.

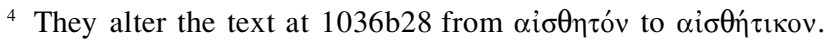


connection by implying that such a soul cannot exist apart from certain bodily organs in which it must be realized.

I believe that this interpretation makes three mistakes. (1) Aristotle is not claiming that definitions of forms allude to matter in the indirect way suggested. (2) In $\mathrm{Z}$ Aristotle does distinguish two kinds of definitions: definitions of forms and definitions of composites. ${ }^{5}$ (3) Aristotle does think that definitions of composites make explicit reference to the matter of the composites. Here I am concerned primarily with (2) and (3). ${ }^{6}$

The position of Frede and Patzig is partly based on the claim that, while the distinction between the definition of the form and the definition of the concrete or composite substance may be made elsewhere by Aristotle, it is nowhere to be found in Meta. $\mathrm{Z}$ and hence cannot be used to explain Z.11's apparent claim (1036b21-32) that some things must be defined in terms of their material parts. ${ }^{7}$ But in fact, I will argue, the distinction is made elsewhere in Z, for example in Z.10, 1035a22-23, where Aristotle says that material parts will not be mentioned in the definition of forms but will be mentioned in the definition of composites. ${ }^{8}$ Likewise, when Aristotle shortly afterward (1035a28-29) refers to entities without matter "whose definitions are of the form alone" the implication is that entities with matter have definitions that are not of the form alone.

I will begin my discussion by concentrating on 1035a22-23 and its surrounding context in $\mathrm{Z} .10$.

Z.10 starts by raising the question of whether the definition of a thing should contain the definition of its parts (1034b20-28). Aristotle begins to

5 In fact, three kinds of definition need to be distinguished. See below, n. 28.

${ }^{6}$ Some other passages outside of Z.10 and 11 which distinguish between definitions of composites that do refer to matter and definitions of forms that do not refer to matter: Meta. 1025b30-1026a6, 1033a1-5, b24-26, 1043a14-18, 1064a19-28; Phys. 194a1-7; De Caelo 277b30-278a6, 23-25; De Anima 403a29-b16.

Previous criticism of the position of Frede and Patzig on definition in Z.10-11 can be found in D. Morrison, "Some Remarks on Definition in Metaphysics Z," in P. Pellegrin (ed.), Biologie, logique et métaphysique (Paris, 1990), pp. 131-44; J. Whiting, "Metasubstance," Philosophical Review C (1991), pp. 626-31; D. Bostock, Aristotle's Metaphysics: Books Z and H (Oxford, 1994); M. Ferejohn, "The Definition of Generated Composites in Aristotle's Metaphysics," in T. Scaltsas, D. Charles, and M.L. Gill (eds.), Unity, Identity, and Explanation in Aristotle's Metaphysics, (Oxford, 1994), pp. 291-318.

7 Frede and Patzig, p. 211.

8 Cf. Morrison, "Some Remarks on Definition in Metaphysics Z," pp. 136-37.

9 Cf. D. Bostock, Aristotle's Metaphysics: Books Z and H, p. 150. 
answer the question by distinguishing different kinds of part (1034b321035a9) which depend on the kind of thing we are talking about. If we are speaking about a form, then a part is a part of a form. If we are speaking about a concrete, sensible object, a composite of form and matter, then a part is to be understand as a material part of the object.

Now, chapter 10 occurs in a section of Z (4-11) which is devoted to the topic of essence (1029b1-13), and since Aristotle identifies essence and form, ${ }^{10}$ Aristotle's focus in chapter 10 is on whether the definition of a form should contain the definition of its parts. So, after drawing his distinction between kinds of part, Aristotle goes on to explain (1035a9-22) that the definition of a form should contain the definition of the parts of the form but should not contain the definition of the parts of the composite, i.e. its material parts.

On Frede and Patzig's translation, Aristotle then goes on to make the following claim in 1035a22-23:

(1) So with some things the definition of such parts will be contained <in their definition>,

(2) (a) whereas with others it must not be contained, (b) unless it deals with the definition of a thing in which matter is included. ${ }^{11}$

I believe that in (1) Aristotle shifts attention from the definition of forms to the definition of composites of form and matter and asserts that such definitions should mention the matter of those composites.

Frede and Patzig claim, by contrast, that the "such parts" mentioned in (1) refer to parts of the form. ${ }^{12}$ Thus, they maintain, appealing to a difference Aristotle has just pointed out (1035a9-22), (1) says that the definitions of parts of a form should be present in the definition of one kind of concrete object - those that are like syllables. Then the "others" of (2) refers to composites of form and matter such as circles, and (2) says that the definitions of the material parts of such composites should not be mentioned in the definition of the forms of these composites.

Difficulty for Frede and Patzig* arises from the fact that they construe both (1) and (2) as speaking about composites, though different kinds of

${ }_{10}$ Meta. 1032b1-2, 1036a16-19, 1037a33-b4, 1043b2-4.

11 “(1) Bei manchen Dingen wird also die Formel von Teilen von dieser Art (in ihrer Formel) enthalten sein, (2) bei anderen dagegen darf sie nicht enthalten sein, es sei denn, es handle sich um die Formel einer Sache, bei der die Materie miteinbezogen ist."

12 Frede and Patzig, p. 180.

13 * See their discussion of this line in Frede and Patzig, pp. 178-79. 
composites. This causes two problems. First, they construe (2)(a) as making a claim about composites such as circles: the definitions of such composites do not refer to their material parts. What, then, can they do with (b)? It states an exception to the claim made in (a) for a certain class of cases: those in which the defined entity includes matter. The entities in question can only be composites. The entities referred to in (a), as construed by Frede and Patzig, are also composites. Why then would Aristotle contrast the entities mentioned in (b) with the entities mentioned in (a) by calling them composites?

Secondly, on Frede and Patzig's account, (a) states that reference to material parts such as the segments of a circle should not be included in definitions of forms of composites such as circles. Since (b) clearly says that what does not hold in the cases mentioned in (a) does hold in certain other cases, Frede and Patzig must understand (b) to say that reference to material parts such as segments must be mentioned in the definitions of some composites. But this is precisely what they claim Aristotle rejects for all definitions. Furthermore (see the preceding paragraph), (b) specifies the class of cases in which reference to material parts such as segments must be mentioned in definitions as those in which the definiendum is a composite. So it appears that Frede and Patzig must construe Aristotle as making this claim for all composites.

Another apparent problem for Frede and Patzig is that they construe (1) so that the things in question are concrete objects such as syllables, while the parts in question are parts of a form. But then since it is, on their view, the definition of composites that is at issue, (1) appears to be speaking of formal parts as parts of the composite. But nowhere in the preceding passage, and nowhere in Z.10-11, does Aristotle speak of parts of a form as being parts of a concrete object. Rather, when he distinguished kinds of parts in 1034b32-1035a9, he pointed out on the one hand the parts of a form and on the other hand the matter of a composite object which is a part of that composite.

It might be suggested that Frede and Patzig need not take (1) to be saying that the "such parts," i.e. the parts of the form, are parts of the composite. Rather, one might suggest, they could construe (1) to be saying merely that the definition of composites must mention "such parts" without at the same time implying that these formal parts are parts of the composite. So while the subject of the sentence ( $\tau \hat{\omega} \nu \mu \grave{\varepsilon} v)$ is composite substances which are like syllables, the "such parts" that (1) goes on to mention are not to be taken as parts of those composites but merely as parts of the form which must be mentioned in defining those composites. 
However, as we shall shortly see, the way in which Frede and Patzig construe the next sentence (1035a24-25) rules this out. For they take the parts mentioned in (1) to be parts of the composites into which those composites perish. ${ }^{14}$

Further, Frede and Patzig are claiming that the kinds of parts at issue in (1) and (2) are different: in (1), they hold, parts of the form are in question while in (2) material parts are in question. But the parts in question must be the same in (1) and (2). In the Greek, the subject of the first

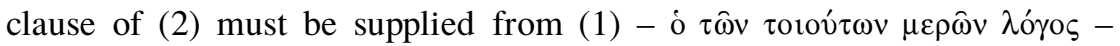
and so whatever the "such" parts are that (1) is talking about, (2) must be talking about the same kinds of parts. Hence, (1) is saying that the definition of the same sorts of parts which according to (2) are not mentioned in the definition of certain items are mentioned in the definition of certain other items.

What sorts of parts, then, are at issue in (1) and (2)? It seems that they must be material parts. (1)'s use of the phrase "such parts" indicates that Aristotle has just been speaking about them. And what he has just been speaking about for the previous eleven lines (1035a12-22) is material parts, explaining that they are not parts of the form. So another difficulty with Frede and Patzig's view that it is parts of the form which - according to (1) - are to be mentioned in definitions, is that they must construe Aristotle as speaking of material parts for eleven lines (1035a12-22), then refer to "such parts" in (1) (1035a22), but mean by the latter phrase not material parts but parts of the form which were last mentioned in $1035 \mathrm{a} 10 .^{15}$

Further problems are created for Frede and Patzig by what follows 1035a22-23, in 1035a24-b1. On their translation, this passage says the following:

a24 Because of this some things consist of things as principles into which they perish, while with other things that is not the case. Now, whatever is so constituted as to include form and matter, as the snub and the bronze circle, decomposes, when it perishes, into its material constituents, and the matter is a part of this thing. On

14 Frede and Patzig, p. 180: "Aristotle distinguishes two cases among things that perish into something, to which he refers with "̌vi $\alpha \mu \grave{\varepsilon} v \ldots$ है $v i \alpha \delta \dot{\varepsilon}$ in a24-25 and with $\tau \hat{\omega} v \mu \grave{\varepsilon} v \ldots \tau \hat{\omega} v \delta^{\prime}$ in a22-23: (i) things [ $\tau \hat{\omega} v \mu \grave{\varepsilon} v$, one kind of concrete object, e.g. a syllable] that perish into parts [i.e. its letters] which at the same time are their principles and therefore must occur in their formula.... The example for the first case is the syllable in its relation to the letters from which it is composed...."

15 Cf. D. Bostock, Aristotle's Metaphysics: Books Z and H, p. 150. 
the other hand, whatever is so constituted as not to include matter, what rather exists without matter and whose definition is of form alone, that does not perish, a30 either not at all or at least not in this way. Consequently these things are principles and parts of those things, but neither parts nor principles of the form. And for that reason the clay statue decomposes into clay, and the circle into earth and Callias into flesh and bones, and further the circle into its segments. For there ${ }^{\mathrm{b}} 1$ is a kind of circle in which matter is included.

Frede and Patzig do not have much to say about 1035a25-b1, but here is what they say about 1035a24-25:

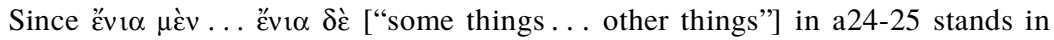
essential parallel to $\tau \hat{\omega} v \mu \grave{\varepsilon} v \ldots \tau \hat{\omega} v \delta$ ' ["some things . . others"] in a22-23, the reference is probably directed to the immediately preceding sentence. The statement a22-23 affirms that there is a kind of thing to whose formula the parts belong essentially. From this, our statement [sc. a24-25] draws the conclusion that the parts into which such things perish are also at the same time principles of the things [sc. the concrete objects] just because they do occur in its formula. The emphasis is on $\dot{\omega} \varsigma \alpha \hat{\alpha} \chi \hat{\omega} v$ ("as from their principles")... .

Aristotle distinguishes two cases among things that perish into something, to

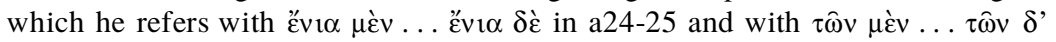
in a22-23: (i) things [concrete objects such as syllables] that perish into parts which at the same time are their principles and therefore must occur in their formula; (ii) things [concrete objects such as circles] that perish into parts which are not principles of them and therefore also cannot occur in the definition. The example for the first case is the syllable in its relation to the letters from which it is composed, for the second case the circle in its relation to the segments.

Therefore from the fact that the syllable decomposes into its letters and these are nevertheless parts of the formula of the syllable, one cannot draw the conclusion that, in general, whatever something decomposes into are parts of its formula. For in the case of material parts ( $\left.\mu \varepsilon^{\prime} \rho \varsigma_{\varsigma} \ldots \dot{\omega}_{\varsigma} \ddot{v} \lambda \eta,{ }^{\mathrm{a}} 16-17\right)$, this does not hold.

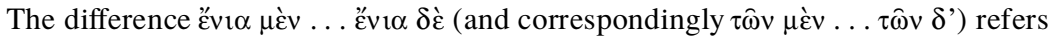
not to the difference between form and concrete object, but rather to the two kinds of concrete object in relation to its parts. Correspondingly he distinguishes between mere material parts and parts (cf. $\tau \hat{\omega} v \tau o$ ov́ $\tau \omega \nu \mu \varepsilon \rho \hat{\omega} v$, a22) such as letters in relation to a syllable. Material parts are parts of the concrete object, but therefore too in no way parts of the form of the concrete object ( $\delta$ ió $\pi \varepsilon \rho$ o $\delta^{\prime}$ ' $\varepsilon v$

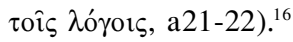

Interpreting 1035a22-b1 along these lines, the passage would proceed as follows:

16 Frede and Patzig, p. 180. 
a22-23: (1) In the case of concrete objects such as syllables ( $\tau \hat{\omega} \nu \mu \grave{\varepsilon} v)$ the definition will contain the definition of such parts [i.e., parts of the form], while

(2) the definition of other sorts of concrete objects such as circles $\left(\tau \hat{\omega} v \delta^{\prime}\right)$ will not contain the definition of such parts [i.e., material parts].

a24-25: (1) Some things such as syllables ("̌vi $\alpha \mu \grave{\varepsilon} v$ ) perish into those things from which they are composed as principles (viz., because the things into which they perish are mentioned in their definition), but

(2) other things such as circles ('̌vi $\alpha \delta \dot{\varepsilon}$ ) perish into parts which are not principles of them (viz., because the things into which they perish are not mentioned in their definition). ${ }^{17}$

a25-30: (1) Composites of form and matter, such as the snub or the bronze circle, perish into those material parts from which they are composed.

(2) Whatever things are not combined with matter but are without matter, whose definitions are of the form alone - these do not perish, either not at all or not in this way.

a30-31: Consequently

(1) these material parts are parts and principles of those things [mentioned in a25-30 (1)], but

(2) these material parts are not parts or principles of the form.

\section{a31-34: Because of this}

(1) the clay statue perishes into clay and the bronze statue perishes into bronze and Callias perishes into flesh and bones and the circle perishes into its segments.

a. For there is a circle which is combined with matter.

There are at least two problems here for Frede and Patzig.

1. Frede and Patzig must say that a22-23 (1) is talking about the parts of the form of a syllable when it speaks of parts whose definition must be mentioned in the definition of the whole. It is certain that a22-23 (1) is not talking about material parts of a syllable as the kinds of parts which are mentioned in the definition of a form, since 1035a14-16 contrasts the parts whose definition is mentioned in the definition of the whole with the sensible, material parts. And 1035a10-11 is explicit that it is the letters which are parts of the form that must be mentioned in the definition of a syllable.

Nor can they avoid commitment to the proposition that in a24-25 (1) the kinds of parts in question are material parts since the parts in question are parts into which a composite perishes. Aristotle does not think

17 I believe it is clear that here Aristotle is not, as Frede and Patzig think, referring to a kind of entity that perishes into elements that are not principles of such entities. Rather, he is referring to a kind of entity that does not, properly speaking, perish at all (1035a29-30). But I will assume the view of Frede and Patzig for now. 
that a concrete object "perishes into" parts of its form. A human being does not "perish into" or "decompose into" the perceptive soul, the nutritive soul, etc. If we take their example of a syllable, 1035a11 and 14-17 clearly distinguish letters which are parts of the form and letters which are material parts of a composite syllable. 1035a14-17 mentions the particular letters which are the perceptible, material parts of the composite syllable. These are the parts into which the perceptible syllable divides, and just as Aristotle says that a particular line perishes into the halves into which it divides (1035a17-18), so the individual perceptible letters into which a composite syllable divides are the parts into which it perishes.

Apart from this, it is unclear what could be meant by saying that the composite syllable perishes into the letters that are parts of its form, and Frede and Patzig make no attempt to explain.

Hence, Frede and Patzig cannot avoid saying that Aristotle slides from speaking about formal parts in a22-23 (1) to speaking about material parts of the syllable in a24-25 (1), even though a22-23 (1) is the justification for a24-25 (1), and even though Aristotle has just (1034b2-1035a9) emphasized the importance of distinguishing these two kinds of parts in order to answer the problem about the parts of the form and definition with which Z.10 is concerned.

2. For Frede and Patzig there is a certain break in the discussion at $1035 \mathrm{a} 25$, so that the discussion divides into the two parts - 1035a22-25 and 1035a25-b3. The first part is discussing two kinds of concrete object, those such as the syllable whose parts occur in their definition and those such as lines whose parts do not occur in their definition. However, while 1035a25-b3 also discusses two kinds of entity, it is perfectly clear that one of the entities discussed in this passage is not any kind of concrete object but rather the form. Nor is there any unclarity about the fact that the other kind of entity is the substance that is a composite of form and matter.

According to Frede and Patzig, in the first part - 1035a22-25 - the following claim was made about those concrete objects and their principles:

The statement a22-23 affirms that there is a kind of thing to whose definition the parts essentially belong. From this, our statement [sc. a24-25] draws the conclusion that the parts into which such things perish are also at the same time principles of the things [sc. the concrete objects] just because they do occur in its definition. The emphasis is on $\dot{\omega} \varsigma \alpha \rho \chi \hat{\alpha} v$ ("as from their principles")....

Aristotle distinguishes two cases among things that perish into something. . . : (i) things that perish into parts which at the same time are their principles and therefore must occur in their definition; (ii) things that perish into parts which 
are not principles of them and therefore also cannot occur in the definition. The example for the first case is the syllable in its relation to the letters from which it is composed, for the second case the circle in its relation to the segments. ${ }^{18}$

But now, in 1035a25-b3 Aristotle again affirms that the parts into which a certain kind of entity perishes are principles of such entities. However, here he affirms that composites of form and matter perish into their material parts and that these material parts are principles of those composites (1035a30). On Frede and Patzig's interpretation this seems to contradict what has been said in 1035a22-25.

Frede and Patzig assert that in 1035a22-25 Aristotle maintains that a concrete object perishes into certain parts as principles because those parts are mentioned in the definition of their form. And the implication appears to be, further, that when a concrete object such as a circle perishes into parts which are not mentioned in the definition of its form (e.g. the segments of a circle), those parts are not principles of the composite.

But here in 1035a25-b3 Aristotle mentions, as examples of parts into which concrete objects perish, parts which are also principles of those concrete objects: the flesh and bones of a human being, the bronze of a circle, and the segments of a circle. This does not appear to make sense on Frede and Patzig's interpretation. For they maintain that the flesh and bones of a human being are not mentioned in the definition of its form and that bronze is not mentioned in the definition of the form of a bronze circle. According to their interpretation of 1035a22-25, Aristotle's conclusion should therefore be that the flesh and bones into which a concrete human being perishes are not principles of the human being; and that the bronze into which a concrete bronze circle perishes is not a principle of the circle. Furthermore, while Aristotle here affirms that the segments into which a concrete circle perishes are principles of the circle, Frede and Patzig asserted that Aristotle just said, in 1035a22-25, that the segments into which a circle perishes are not principles of it on the grounds that such segments are not mentioned in the definition of the form of a circle.

Since 1035a25-b3's statement about segments being principles of the concrete circle that perishes into them is clear, it appears that it is Frede and Patzig's claim about 1035a22-25 that must go.

Note how straightforward our passage is if (1) throughout is taken to refer to one of the kinds of entity distinguished in 1034b32-1035a9, viz.

18 Frede and Patzig, p. 180. My italics. 
composites in general, and (2) throughout is taken to refer to another one of the kinds of entity distinguished in 1034b32-1035a9, viz. forms. ${ }^{19}$ Then all of the problems mentioned above will disappear.

So already in Z.10, I believe, Aristotle distinguishes between definitions of composites which refer to matter and definitions of forms which do not. Likewise in Z.7, 1033a1-5 Aristotle explains that the definition of the composite bronze sphere must mention bronze. These definitions that mention material parts of composites also put in an appearance in Meta. H. 1043a5-11, where the composite house is defined as stones and wood

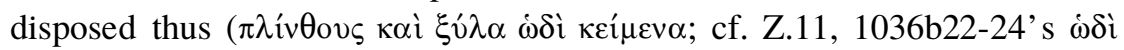
$\tau \alpha \delta$ ì ह̌ $\chi 0 v \tau \alpha ;$ De Part. Anim. 640b22-27).

Hence, when Aristotle says at Z.11, 1036b22-24, that not "all" things can be defined without mentioning matter and explains that

(i) the definition of "some" things must mention matter

"for

(ii) some things are this form in this matter,"'20

he is repeating what was already said in chapters 7 and 10. The justification (ii) offers in support of (i) shows that the things mentioned in (i) as definable only in terms of matter are composites of "this form in this matter." (ii) offers no support for the view that things which are not "this form in this matter," e.g. forms, are to be defined in terms of matter. The difference between composites and forms is, of course, crucial to the entire argument of Z.10-11, with Aristotle emphasizing throughout that many terms referring to concrete objects can be understood to refer either to the composite or to the form alone. ${ }^{21}$ If, as Aristotle says in 1036b22-24, it is the fact that something is "this form in this matter," viz. a composite, which justifies the assertion that the item's definition must refer to matter, and if the definition of forms must be distinguished from the definition of composites, then the implication is that the definitions of items which are not cases of "this form in this matter" should not refer to matter.

${ }^{19}$ My view of the passage is set out in an appendix.

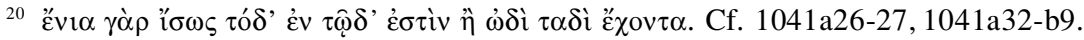

21 1033b17-18, 1035a6-17, b1-3. Cf. the start of H. 3. Passages where such a term refers to a form alone: 1032a18, 23, 1033a27-28, 29, 33, b9, 1034b11, 1035a9-11 (cf. 14-16), 1036a1, 17, 18, 1037a7-8. Cf. De Caelo 278a13-15, De Gen. et Corr. 321b2223,33 . 
This interpretation of $1036 \mathrm{~b} 22-24$ is confirmed by the fact that when Aristotle (Z.11, 1036b22-32) explains that animal (or man) must be defined in terms of material parts, the animal in question is said to be perceptible (1036b28-29). We know from H.3, 1043a34-37 that "animal" can signify either soul (cf. 1036a17) or soul in body. Since a soul is imperceptible (Top. 126a22-24), the perceptible animal mentioned at Z.11, 1036b28-29 is the composite of soul in body ("this form in this matter" or "this matter disposed thus") and not the soul, i.e. the form, alone. So the animal and man which Z.11, 1036b22-23 says must be defined in terms of material parts is the composite substance, not the form.

Frede and Patzig alter the text at 1036b28 from " $\alpha i \sigma \theta \eta \tau$ óv" to " $\alpha i \sigma \theta \eta$ -

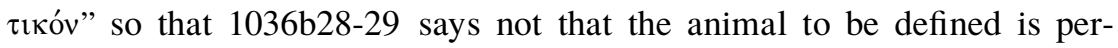
ceptible but that it is able to perceive. There are at least four reasons for rejecting this emendation. (1) It is not found in any manuscripts. (2) " $\alpha i$ $\sigma \theta \eta \tau$ óv" recurs in the immediately following passage (1036b32-1037a5) where it appears to refer back to the present passage. And there the perceptibility of the parts of an object is tied to the question of whether the definitions of the parts occur in the definition of the whole. ${ }^{22}$ (3) While Frede and Patzig refer $^{23}$ to $1035 \mathrm{~b} 18$ for support, the true parallel with Z.11's discussion is Meta. E.1, 1025b30-1026a6, where Aristotle distinguishes items which are and items which are not defined in terms of matter on the basis of the fact that the former do and the latter do not contain "perceptible matter" (1025b34). This fact is then - as in Z.11, 1036b2829 - linked to the fact that the composites containing perceptible matter are indefinable apart from change (1026a2-3). Since E.1 connects the definition of certain entities to these entities' perceptibility, it is not acceptable to alter the text of Z.11 so as to avoid what, according to all our manuscripts, is the same connection at $1036 \mathrm{~b} 28-30 .{ }^{24}$

(4) Their reason for rejecting " $\alpha i \sigma \theta \eta \tau$ óv" is inadequate. They say that if Aristotle is saying that the definition of animal must mention matter, then he is here failing to note the difference in the relations between matter and form in the case of living things and in the case of artifacts, since the latter also contain perceptible matter. They claim that the reference to a

22 Note, however, that the presumption of the argument in 1036b32-34 is that the fact that a part is perceptible is a reason for excluding its definition from the definition of the whole. I take this to confirm that the previous passage does not question the point that wholes which do not contain perceptible parts, viz. forms, are not defined in terms of perceptible parts.

23 Frede and Patzig, p. 210.

${ }^{24}$ Cf. J. Whiting, "Metasubstance," pp. 627, 630-31. 
hand in $1036 \mathrm{~b} 31$ shows that Aristotle has this difference in mind, viz. the difference that the matter of an animal is an ensouled body not capable of surviving the animal's death in the way an artifact's matter can survive the artifact's destruction. ${ }^{25}$

But there is no reason why this difference between artifacts and animals must affect the point Aristotle is making here. The crucial point is that Aristotle uses the example of the hand to support the contention (1036b29-30) that an animal cannot be defined "without its parts being in a certain condition." But it is equally true that one cannot define an artifact without "its parts being in a certain condition." One cannot make a house out of mercury or air. The form of a house can only be realized in matter that is "in a certain condition." Since Aristotle is using the example of an animal in the passage, he explains the way in which the matter of a hand must be in a certain condition in the case of animals. The fact that the specific explanation of why the matter of animals must be in a certain condition does not apply to artifacts does not mean that there is not some other explanation of why the matter of artifacts must be in a certain condition for the forms of artifacts to exist.

That the difference between artifacts and living things which Frede and Patzig appeal to is not relevant to Aristotle's point is supported by H. 2. There, when Aristotle explains that definitions of composites refer to their matter, he compares the definitions of composite living substances and artifacts by saying: "Just as in the case of substances [i.e., living things] what is predicated of matter is the actuality itself, thus in other definitions" (1043a5-7), including definitions of artifacts.

Frede and Patzig appeal to $1037 \mathrm{a} 21 \mathrm{f} .{ }^{26}$ as support for the claims that matter is mentioned in no definition, and that Aristotle does not speak of a definition of the composite other than a definition of the essence of the composite. ${ }^{27}$ But this appeal is not convincing since 1037a21f. is con-

25 Frede and Patzig, p. 210.

${ }^{26}$ Frede and Patzig, p. 190; cf. p. 211; M. Frede, "The Definition of Sensible Substance in Metaphysics Z," pp. 116-17. Morrison agrees ("Some Remarks on Definition in Metaphysics Z," p. 137), and so thinks Aristotle here contradicts his earlier contention that the definition of the composite refers to matter. I disagree with Morrison in that I do not think that Aristotle believes that a definition of a composite specifies only its essence. I take Aristotle to identify the essence of a composite such as a man with the essence of its soul, as in 1043b2-4. Here man, i.e the composite of soul and body (1043a34-35), is distinguished from the essence of man (i.e. soul) and has a different definition (1043a36-37).

${ }^{27}$ Cf. D. Bostock, Aristotle's Metaphysics: Books Z and H, p. 151. 


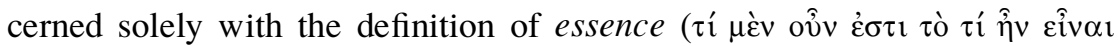

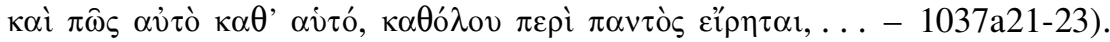
The context (1037a21-b5) focuses entirely on the topic of essence, summarizing main points which have been established during the examination of essence in Z.4-6 and 10-11. Aristotle begins by noting that it has been explained what essence is and how it exists in itself (a21-22). He then (a22-33) discusses the definition of essence and finally (a33-b7) considers the question of the identity of essence with certain items. This focus on essence in summing up the preceding chapters of $\mathrm{Z}$ is hardly surprising since essence is one of the four main candidates for primary substance (1028b34), and at the beginning of Z.4, the start of the discussion which he now summarizes, he pointed out that it was the topic of essence that was to be examined.

In the section of 1037a21f. on definition (a22-33), Aristotle explains that

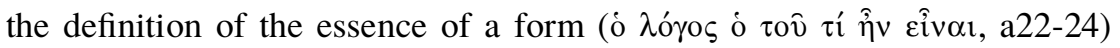
will mention its parts while the definition of the essence of a composite will not mention its material parts. ${ }^{28}$ The definition of the essence of the composite man, for example, will not mention the material parts of a man because the essence of a man is its soul (1043b2-4), and so this definition will not mention the matter of a man for the same reason that the definition of the soul will not mention the matter of a man.

In a27-28, Aristotle goes on to say that, in a way, however, there will not be a definition of the essence of the composite in that no such definition (i.e., no definition of the essence of a composite) will mention the material parts of the composite. Although this sentence (a27-28) only uses

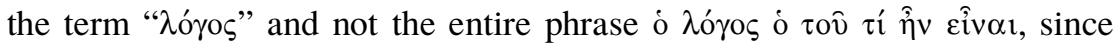
the entire passage is about essence, and a22-24 does speak explicitly of

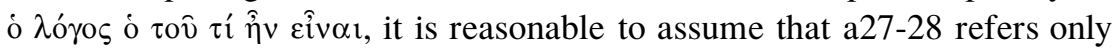
to the definition of essence.

If I am correct, then 1037a22-33 does not show that there is no

28 Similarly, as throughout Z.10-11, it is the pair "form - composite" that is in question in the last section of the passage (a33-b7), where Aristotle says that a form is identical to its essence while a composite is not identical to its essence.

The passage indicates that there are at least three different cases of definition that must be distinguished: (i) the definition of the essence of a form, which is what a definition of a form will always amount to; (ii) the definition of the essence of a composite, which will display only the form, i.e. the essence, of the composite (cf. 1043b2-3); (iii) the definition of a composite which will not merely display its essence but the matter in which the essence is realized. 
definition of the composite that mentions matter since it deals solely with the definition of the essence of an item, where that item is in some cases a form and in other cases a composite of form and matter (a22-24). 1037a27-28's assertion that the definition of the essence of a composite does not mention matter does not show that there is not some other kind of definition of the composite that does mention matter. Since 1037a21b7 is summarizing the discussion which Aristotle has just carried out in Z.4-6 and Z.10-11, and since that discussion has focused on the notion of essence, it is not surprising that Aristotle's résumé of the preceding discussion does not refer to definition of composites as well as to the definition of essence.

The same point applies to 1035b31-34. There Aristotle says that "only parts of the form are parts of the definition," but he is thinking solely of definitions of forms. Similarly, at 1035a19-21 he asserts that material parts are not parts of the form or of the definition just before he explains that the definition of material parts will occur in the definitions of some things (1035a22-23). On the other hand, when Aristotle says in H.6, 1045a 3335 that "Of matter, one kind is intelligible and another kind is perceptible, and it is always the case that one part of the definition is matter and another part actuality," he is thinking of definitions of composites alone despite the "always." Thus, he goes on to say (1045a36): "But whatever things do not have matter, either intelligible or perceptible ...”. 


\section{APPENDIX}

\section{A22-B3:}

Aristotle has distinguished parts (1) of a form from material parts (2) of the composite.

\section{A. $1035 a 22-23$}

The definitions of composites differ from the definitions of forms:

1. The definition of material parts (2) will occur in the definition of composite substances.

2. The definition of material parts (2) will not occur in the definition of forms.

B. $1035 a 24-31$

Because of (A1):

In the case of composites such as the bronze circle:

1. Material parts (2) are parts (2) of the composites.

2. Material parts (2) are principles of the composites.

3. Composite substances are constituted from material parts (2).

4. Composite substances perish into material parts (2) from which they are constituted as principles.

Because of (A2):

In the case of forms, whose definitions (by contrast) are of the form alone:

1. Material parts (2) are not parts (1) of the forms.

2. Material parts (2) are not principles of the forms.

3. Forms are not constituted from material parts (2).

4. Either:

1. Forms do not perish at all, or

2. Forms do not perish into material parts (2) from which they are composed as principles.

C. 1035a31-b3

Because of what (A) and (B) state about composites, they perish into their matter.

Examples:

1. The clay statue perishes into clay.

2. The bronze sphere perishes into bronze. 
3. Callias perishes into flesh and bones.

4. The circle perishes into its segments.

1. For there is a kind of circle which is combined with matter.

2. For both the circle simply - the form - and the particular circle - the composite - are called a circle.

3. For the name is not applied only to particular circles, i.e. composites.

University College London 